\title{
Chronic toxicity bioassay with populations of the crustacean Artemia salina exposed to the organophosphate diazinon
}

\author{
Eduardo Bustos-Obregon \& Álvaro Vargas \\ Laboratory of Biology of Reproduction, School of Medicine, University of Chile, Santiago, Chile
}

\begin{abstract}
A chronic toxicity bioassay was conducted with the microcrustacean Artemia salina as the testing organism for the toxic organophosphate diazinon in order to determine if the species is an appropriate indicator of pollution in aquatic environments. Tests of animal exposure to different concentrations of the toxicant were performed for 24, 48 and 72 hours after larvae hatching. Registered mortality data was used to obtain the lethal dose $50\left(\mathrm{LD}_{50}\right)$ of the organophosphate for each exposure time, considering the immobilization of A. salina larvae as the mortality parameter. The lethal concentration $\left(\mathrm{LD}_{50}\right)$ in the same exposure times was calculated by evaluating morphological changes on the three initial stages of larval development. Both doses were determined by using probit statistical analysis. Results indicate greater dose-response exactitude after 24 hours of exposure to the toxicant. High sensitivity of the organism to the toxicant was determined, thus indicating that A. salina is an appropriate ecotoxicological bioindicator of aquatic environments polluted with pesticides, with the special consideration that this species is a natural resident of saline water bodies, and thus could be used to control pollution in these environments as a result of the unrestrained usage of such toxic substances.
\end{abstract}

Key terms: Diazinon, Artemia salina, ecotoxicology, bioassay.

\section{INTRODUCTION}

Toxicological bioassays are currently the most commonly used tests to determine the effectiveness of certain species as bioindicators and to evaluate pollution in the environment. These studies are intended to obtain results rapidly and at a low cost. A bioassay is a test that involves living organisms to analyze substances in terms of the biological response they produce (Silva, 2002). They evaluate the degree of damage of a chemical substance to living organisms after chronic or acute exposure. Acute tests quantify the lethal concentrations of a xenobiotic on any particular species. The calculated value is termed a lethal dose $\left(\mathrm{LD}_{50}\right)$ and corresponds to the concentration of a xenobiotic that provokes death in $50 \%$ of an experimental population after a given exposure time, generally 24 or 48 hours. Chronic trials estimate the mean effective concentration (EC50) of the test substance that causes an effect on $50 \%$ of an experimental population after a determined exposure time (over 48 hours) (Rodriguez \& Esclapés, 1995). Currently, if herbicides, fungicides and insecticides are considered as a whole, all cases of acute intoxication are due to insecticides that inhibit enzyme acetylcholinesterase, with the consequent accumulation of elevated levels of acetylcholine in nervous synapses. Thus, a series of cholinergic signals that could lead to death are produced (Henao \& Corey, 1986). Within this group, organophosphorous pesticides are particularly important because of the rise in sales of products with this kind of substance since the ban of organochlorinated pesticides (Ortega et al., 1994).

Although the purpose of pesticide usage is to eliminate undesired organisms that could damage crops or transmit diseases to animals and humans, there are other living organisms -including humans- whose physiological or biochemical functions are similar to those of the species of interest to be eliminated and that are sensitive to different degrees to the toxic effects of chemical pesticides, thus their use as chemical weapons (Barnes, 1976; Ortega et al., 1994). The preferred route of propagation of organophosphates is the aqueous pathway. The contamination of water bodies is generally due to crop treatments, farm disinfections and industrial wastes.

The brachiopod crustacean Artemia sp. has been commonly used as larval food for fish and crustaceans in aquaculture (Varó et al., 2003). The common habitats for this species are coasts and shallow saline water, which are usually close to agricultural areas. Organophosphorous pesticides, commonly used in agriculture, are a danger for Artemia populations due to its toxicity, especially considering that this is a target species for its capacity of bioaccumulation. This factor is of great importance because the accumulation of the pesticide in Artemia tissue that could reach the aquatic trophic chain, to which Artemia is one of the first links (Varó et al., 2003). Therefore, a chronic toxicity bioassay with the microcrustacean Artemia salina as testing organism for the toxic organophosphate diazinon was performed in the present work in order to determine if that species is an appropriate indicator of pollution in aquatic environments.

\section{METHODS}

As a test organism, populations of the brachiopod microcrustacean Artemia salina were obtained from dehydrated eggs purchased in a specialized store. Eggs were developed under proper conditions for hatching and manually separated into subpopulations of 20 individuals at 24, 48 and 72 hours of life. They were not fed during those periods since their digestive system is still non-functional. The xenobiotic used was the commercial organophosphate diazinon, under the brand name Diazinon 60E from IDA Laboratories (Memphis, TN, USA), at a concentration of $60 \%$ $\mathrm{w} / \mathrm{v}$. 
In order to obtain the populations of Artemia salina, dehydrated eggs were cultured under the following conditions: Temperature - cultures were exposed to a constant environmental temperature of $26^{\circ} \mathrm{C}$ in thermoregulated chamber for the 72 hours of the assay. Light - fluorescent bulbs were used with a light:darkness cycle of 12:12 hours in the thermoregulated chamber. Culture flasks 5-liter polypropylene flasks were used. Water dilution water - tap water with a salinity of 32.5 grams per liter was used, with common sea salt obtained from a specialized store. Culture density - the number of cultured eggs was 1 gram per liter of water. Air supply - a saturated oxygen condition was provided by an aquarium air pump. Once the eggs were hydrated under this condition, Artemia salina cyst hatching was produced. After 24 hours of egg hydration, the culture exhibited individuals in the stage of nauplium I, the first larval stage of early normal development. Twenty individuals were manually removed with a pipette and placed in $20-\mathrm{mL}$ flasks filled with a fixative solution of $10 \%$ formalin. Nauplii were left in the solution for 10 minutes, the time necessary to produce immobility in the specimens in order to analyze their normal morphology at this stage of development, using a microscope with 10X magnification. The same methodology was applied at 48 and 72 hours posthatching to compare our own morphological observations to prior bibliographical reports. Results in each interval showed that all individuals exhibited the normal morphological characteristics reported for their respective stages of normal early development, as illustrated in photographs of the individuals at the three aforementioned stages:

First larval stage: Photograph taken 24 hours posthydration (Fig. 1A). The presence of the nauplium eye, the first pair of appendages or antennae, the second pair of appendages or antennae and the third pair of appendages or mandibles were observed. The characteristic brownish color was noted as an index of good health. Appendages were symmetrical in length and width. There was no evidence of developmental anomalies.

\section{Second larval stage:}

Photograph taken 48 hours post-hydration (Fig. 1B). The presence of the same appendages of the previous stage was noted, with a brief growth that maintained symmetry in length and width. The anal opening, a characteristic
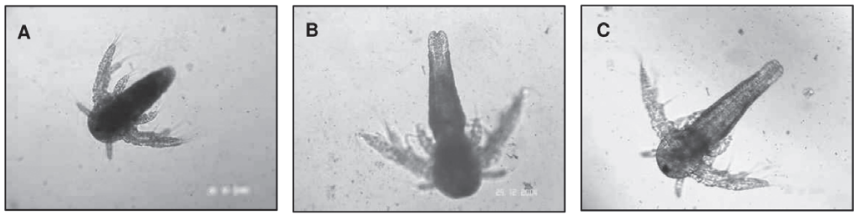

Figure 1: First (A), second (B) and third (C) larval stage of Artemia salina after 24,48 and 72 hours post-hatching, respectively. (A) note naupliar eye (a) the first pair of antennae (b) second pair of appendages or antennae (c) third pair of appendages or mandible (d) (arrows) normal brown colour and symmetric length and width of the appendages $(12.5 \mathrm{X}$ magnification). (B) anal perforation (arrow), characteristic of this nauplii II stage (9.4X magnification). (C) the three normal pairs of appendages are more developed and linear digestive tract (arrow) (7.5X magnification). phenomenon in the normal development of stage II nauplium, was noted. The specimens showed the normal brownish color, without any evidence of developmental anomalies.

\section{Third larval stage:}

Photograph taken 72 hours post-hydration (Fig. 1C). The three pairs of appendages were noted, with greater development and growth. The presence of a lineal digestive system was observed, as characteristic of this stage. Specimens were normally brownish in color. There was no evidence of developmental anomalies. It was concluded that under ideal culture conditions, eggs hatched normally and Artemia salina nauplii exhibited a morphologically normal development during their first three developmental stages.

In the preliminary toxicity assay, a population of Artemia salina was cultured under the following conditions: a 5-liter polypropylene container was filled with 2 liters of tap water with 65 grams of iodide-free salt diluted to obtain the proper salinity; 2 grams of dehydrated Artemia salina eggs were introduced. The container was maintained at a controlled temperature of $26 \pm 2^{\circ} \mathrm{C}$ in the thermoregulated chamber, with a 12:12 hours light-darkness regime and oxygen saturation.

As a preliminary assay, a series of dilutions with different concentrations of diazinon were obtained to determine the interval of sample concentration for the definitive assays (Vargas and Bustos-Obregón, 2006). We determined the concentration ranks after 24 and 72 hours of exposure to diazinon, in which $0 \%$ and $100 \%$ of mortality were observed. With the data obtained from this assay, the $\mathrm{LD}_{50}$ was calculated for the organophosphate diazinon in the nauplii of Artemia salina at 24, 48 and 72 hours of exposure, using probit analysis as the statistical method. The assay was performed by hydrating the eggs under ideal conditions for two hours to stimulate nauplii hatching. Then 20 nauplii of Artemia salina were manually removed from flasks and subdivided into 4 groups of 5 individuals per each dilution and placed in sterile glass flasks filled with water obtained from the main culture flask containing serial dilutions of diazinon for dosage testing in a total volume of $20 \mathrm{~mL}$ per sample controlling nauplii survival and morbidity rates every 8 hours until completing a total of 72 hours of exposure. In the assay, 8 dilutions were tested with decreasing concentrations of diazinon, considering a control group without exposure to the pesticide for every 2 dilutions of diazinon. Once the $0 \%$ and $100 \%$ mortality ranks were obtained in the preliminary assay, a definitive test for chronic toxicity was performed to determine the $\mathrm{EC}_{50}$ (mean effective concentration) for the organophosphate diazinon in Artemia salina, based on morphological changes analyzed after 24, 48 and 72 hours of exposure to the pesticide. Artemia salina populations of 20 individuals each (subdivided into 5 subgroups) were used for every diazinon concentration tested. For each dilution, 3 groups of 20 individuals were assayed: one with 24 hours of exposure, another with 48 hours and the last with 72 hours of exposure. A total of 10 dilutions were evaluated, with 3 different concentrations of diazinon and were compared to the control group of 20 individuals unexposed to the pesticide. Replicas of 5 individuals each were incubated in $25 \mathrm{~mL}$ glass flasks filled with $20 \mathrm{~mL}$ of a dilution of diazinon in saline water from the 
main culture. Once the exposure times were completed, test individuals were fixed with a $10 \%$ formalin solution for subsequent analyses under a microscope with $10 \mathrm{X}$ magnification to determine the morphological alterations in samples compared to the control group.

\section{RESULTS}

Preliminary bioaasay $\left(\mathrm{LD}_{50}\right)$ : The first group of $\mathrm{A}$. salina larvae (group A) was submitted for 72 hours to an initial concentration of $29.4 \mathrm{mg} / \mathrm{L}$ of the organophosphate diazinon; the second group (B) was exposed to $14.0 \mathrm{mg} / \mathrm{L}$ (half of the initial dose) and the third group -controlremained unexposed to the toxicant. Because the mortality rate for Group A was 100\% after the first two hours of exposure, the referential dose was considered too high, so it was reduced by half. A low percentage of survival was registered in Group B after two hours and by eight hours mortality had reached $100 \%$ of the sample. The control group showed $100 \%$ survival after 72 hours of assay.

After the first trial, a new larval population was exposed to lower concentrations. Group C was tested with a concentration of $9 \mathrm{mg} / \mathrm{L}$ diazinon, registering survival after 16 hours of exposure. The second group was treated with 6 $\mathrm{mg} / \mathrm{L}$ of diazinon and exhibited a notable increase in larval resistance, with survival until 48 hours of exposure. The control group showed no mortality until 72 hours of assay. Group E received a concentration of $4 \mathrm{mg} / \mathrm{L}$ and exhibited survival until 56 hours of exposure. It registered $100 \%$ of survival after 24 hours, which is important information for the final bioassay. Group F showed survival until 72 hours of exposure with a concentration of $3 \mathrm{mg} / \mathrm{L}$; it also showed $100 \%$ survival until 48 hours of exposure, another relevant parameter. The respective control groups did not show any variations. Group $\mathrm{G}$ was exposed to $2 \mathrm{mg} / \mathrm{L}$ of diazinon and showed $100 \%$ resistance and survival after 72 hours of exposure. Group $\mathrm{H}$ received $1 \mathrm{mg} / \mathrm{L}$ and showed the same results as group $\mathrm{G}$. Thus, this preliminary trial gave the parameters for the definitive assay to determine the $\mathrm{EC}_{50}$; this assay must be performed by intoxicating Artemia populations to analyze 186 early developmental alterations after 24,48 and 72 hours of exposure to diazinon.

\section{Data Analysis}

The determination of the $\mathrm{LD}_{50}$ (or $\mathrm{ED}_{50}$ ) requires of quantal statistics, so it is necessary to transform the response values into anglit, logit or probit units (the latter were used in this work). As well, the doses used need to be transformed into logarithmic units known as metametric doses. Specialized computer software resolves this type of calculation (in our case, we employed the program Microsoft Excel 2000), but the reliability depends on the person or institution. The comparison of the procedures employed is necessary, as well as developing media for their simplification.

The general objective of our research is to provide parameters for the development of a bioactivity analysis using the probit method. The main objective of this kind of analysis is to evaluate the necessary level of stimulus to obtain a response in a group of individuals of a population. The level of stimulus that provokes a response in $50 \%$ of the population under study is an important characterization parameter known as $\mathrm{LD}_{50}$, for mean lethal dose (or $\mathrm{ED}_{50}$ for mean effective dose, $\mathrm{EC}_{50}$ for mean effective concentration, or Mtl for mean tolerance limit). The duration of exposure to the stimulus must be specified (e.g. 24 hours DL50) to compare and estimate the relative potency of the stimulus (Hubert, 1980). With the data obtained in the preliminary assay, $\mathrm{LD}_{50}$ was obtained through probit analysis at 24,48 and 72 hours of exposure to diazinon for Artemia salina larvae. Figure 2A represents the data obtained at 24 hours of exposure. The Y-axis (probit) indicates the percentage of dead individuals after 24 hours of exposure to the toxicant, while the $\mathrm{X}$-axis represents the logarithm of every dose used in the bioassay. The tendency line obtained considers the points at which there were $0 \%$ and $100 \%$ of mortality, as represented by the first degree equation $y=2.8394 x-1.7095$ with an $R^{2}=1$, which indicates the number of points represented by the tendency line within a range from 0 to 1 . The greater the $R^{2}$ value, the more significant the results are, accepting as significant an $\mathrm{R}^{2}$ value starting from 0.85 (85\%). To obtain $\mathrm{LD}_{50}$, the equation was calculated for a $\mathrm{y}$ value of 0.5 and an $x$ value was obtained and the antilogarithm was calculated for it, obtaining a final result of $6 \mathrm{mg} / \mathrm{L}$ as $\mathrm{LD}_{50}$ in the population exposed to the toxicant for 24 hours.
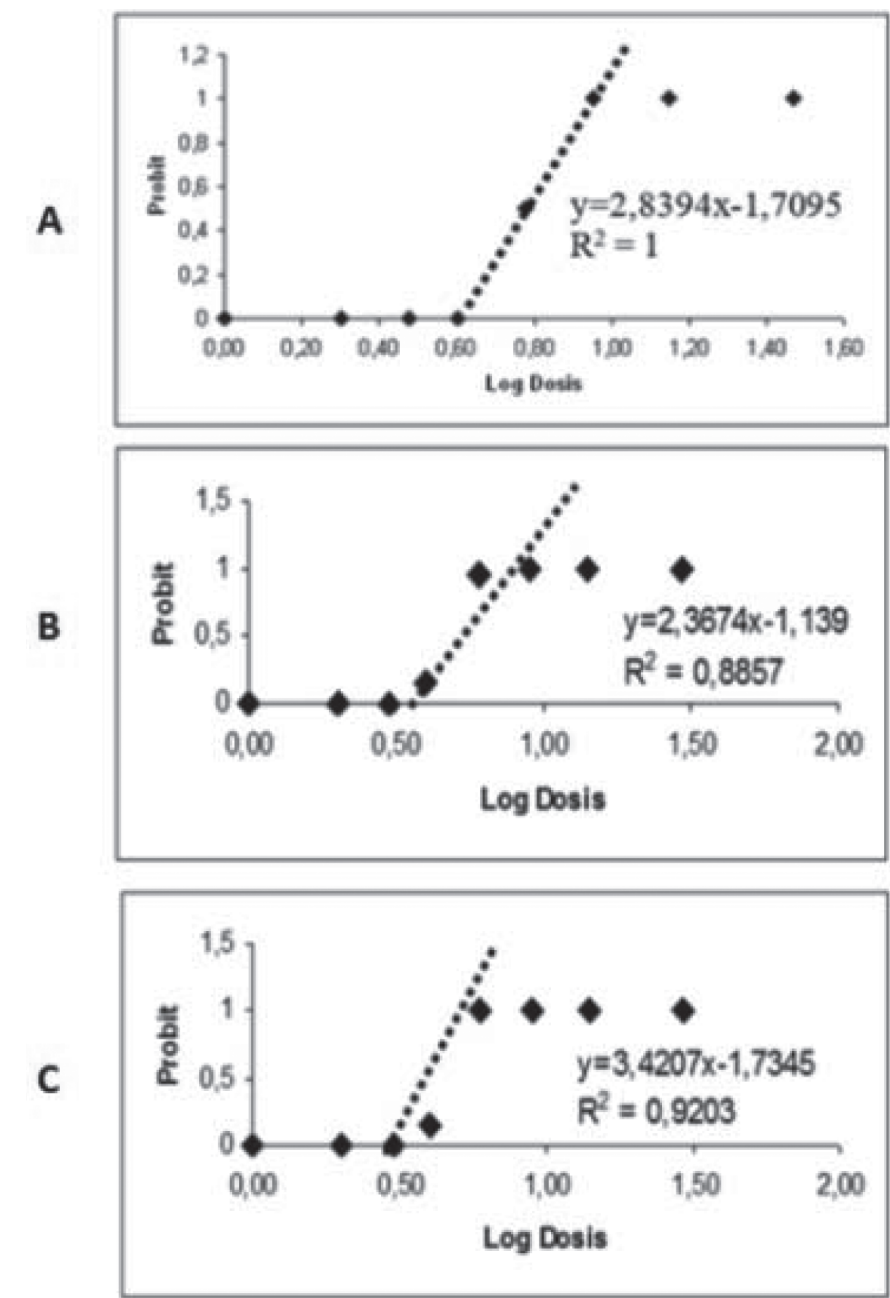

Figure 2: $\mathrm{LD}_{50}$ obtained through the Probit analysis at 24, 48 and 72 hours of exposure to diazinon for Artemia salina larvae. 
Subsequently, data obtained from the exposure of larvae to the toxicant for 48 hours were graphed, calculating the $\mathrm{LD}_{50}$ by probit analysis in $4.924 \mathrm{mg} / \mathrm{L}$ with an $\mathrm{R}^{2}=0.88(88 \%)$, which implies that the points in the tendency line are representative (Figure 2B). Figure 2C shows that after 72 hours of exposure, the probit analysis gave an $\mathrm{LD}_{50}$ of 4.5 $\mathrm{mg} / \mathrm{L}$ and $\mathrm{R}^{2}=0.92$ (a significance of $92 \%$ ).

Results of the final bioassay $\left(E C_{50}\right)$

Results obtained and registered in the control card are presented. Larvae in Group A were exposed to a concentration of $4 \mathrm{mg} / \mathrm{L}$, obtaining morphological alterations in $100 \%$ of the population in every period of exposure (24, 48 and 72 hours). The dose of diazinon for Group B was reduced to $3 \mathrm{mg} / \mathrm{L}$, and a reduction in the percentage of altered individuals after 24 and 48 hours was noted, but $100 \%$ of larvae were altered at 72 hours of exposure. A dose of $2.6 \mathrm{mg} / \mathrm{L}$ was used for Group C and results were similar to those obtained with $3 \mathrm{mg} / \mathrm{L}$. Group D received a dose of $2.3 \mathrm{mg} / \mathrm{L}$ of diazinon and exhibited for the first time a reduction in the alteration percentage after 72 hours of exposure. Group E was exposed to $2 \mathrm{mg} / \mathrm{L}$ of diazinon, registering $50 \%$ of altered individuals by 24 hours. Group F received a dose of $1.6 \mathrm{mg} / \mathrm{L}$ and exhibited $50 \%$ of altered individuals by 48 hours. Group G received $1.3 \mathrm{mg} / \mathrm{L}$ diazinon and maintained the tendency of percentage reduction of altered individuals in the 3 periods of time. Group $\mathrm{H}$ exhibited $50 \%$ of altered individuals after 72 hours of exposure with a dose of $1 \mathrm{mg} / \mathrm{L}$. In groups $\mathrm{I}, \mathrm{J}, \mathrm{K}$ and $\mathrm{L}$, lower doses were used until $0 \%$ of alterations were detected in every period of time.

\section{Statistical analysis}

With all registered data, the $E_{50}$ was calculated for the 3 exposure periods with the probit analysis. Figure $3 \mathrm{~A}$ shows the results obtained after 24 hours of exposure of the individuals to diazinon. The $\mathrm{Y}$-axis represents the percentage of individuals with morphological alterations and the $\mathrm{X}$-axis shows the doses used, expressed as logarithms. The tendency line showed an $\mathrm{R}^{2}=0.95(95 \%$ significance). In this case, the doses, represented in $\mathrm{mg} / \mathrm{L}$, were expressed in $\mu \mathrm{g} / \mathrm{L}$ in order to graph the data. The result of the analysis gave an $\mathrm{EC}_{50}$ of $1867.50 \mu \mathrm{g} / \mathrm{L}$ in individuals exposed to diazinon for 24 hours. In the case of the population exposed for 48 hours to diazinon, the Probit analysis gave a EC $50=1271.80 \mu \mathrm{g} / \mathrm{L}$, with a level of significance $\mathrm{R}^{2}=0.848(85 \%)$, a very value compared to that observed in the population of A. salina larvae exposed to the toxicant for 24 hours (Figure 3B). In the population exposed for 72 hours to diazinon, the analysis gave an $\mathrm{EC}_{50}=866.67 \mu \mathrm{g} / \mathrm{L}$ with $\mathrm{R}^{2}=0.8911(89 \%)$, a good value of significance for the tendency line (Figure 3C).

Morphological alterations in the population exposed to diazinon Nauplii 1 (24 hours)

-Asymmetry in growth speed that results in asymmetry of appendage size (Figure 4A). Augmentation of appendage width (Figure 4A) - Longer filtrating chaetae produced by tissue retraction (Figure $4 \mathrm{~B}$ ).
Nauplii 2 (48 hours) - Failure in development of the third pair of appendages, with mandible function (Figure 5A). Absence of anal opening (Figures 5A, 5B). -Persistent darker color, signal of abnormality. Metanauplii (72 hours) Agenesia of the first pair of appendages (antennae with
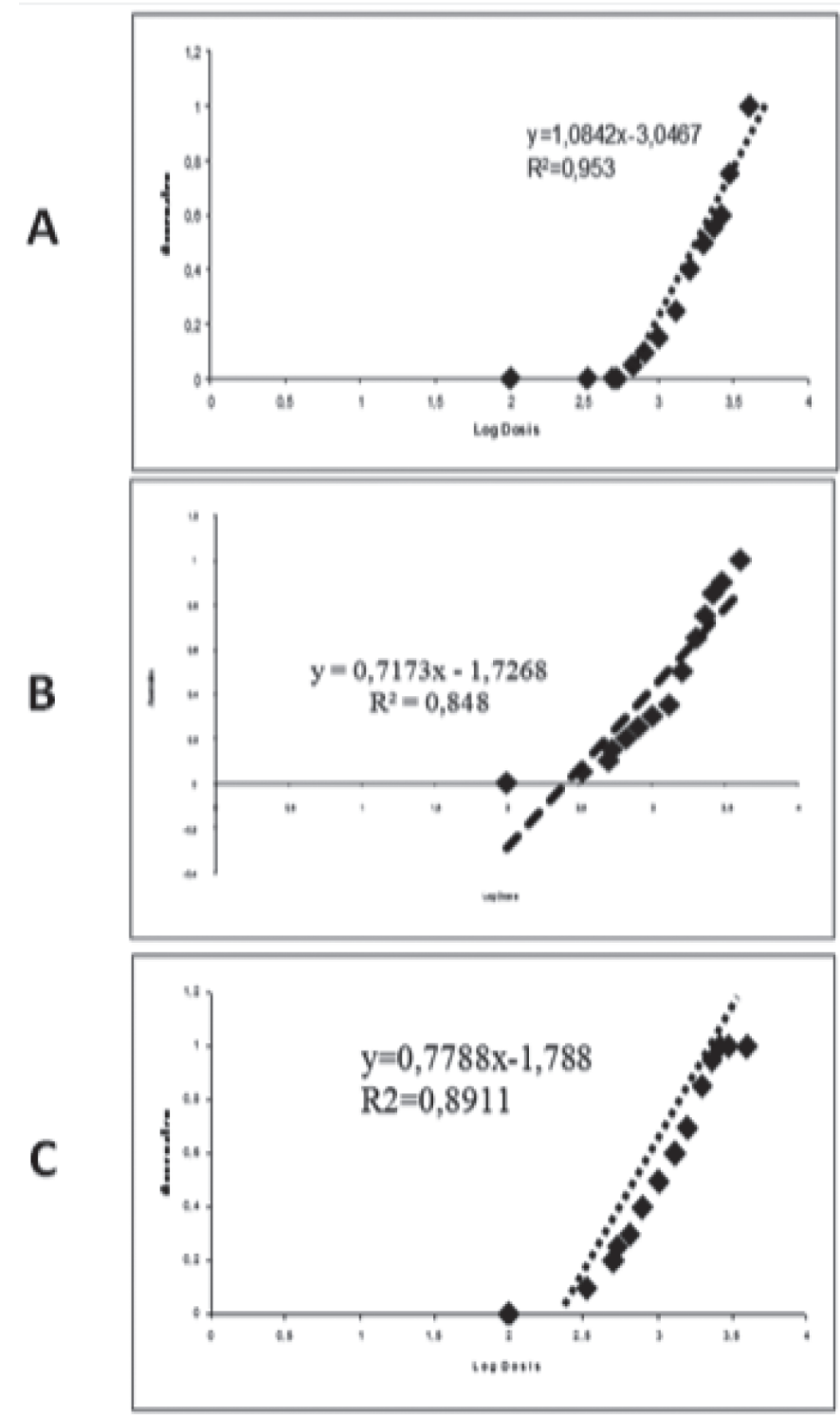

Figure 3: EC50 obtained through the Probit analysis at 24, 48 and 72 hours of exposure to diazinon for Artemia salina larvae.

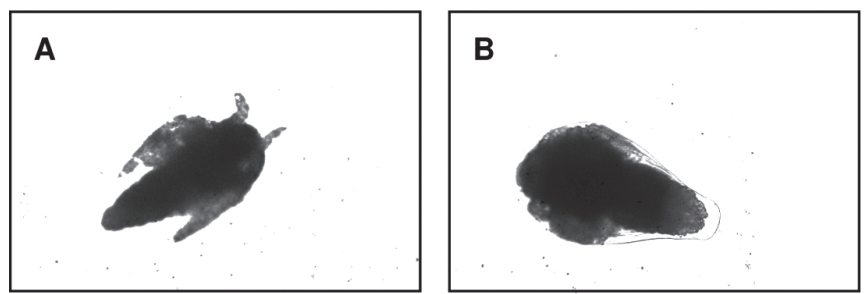

Figure 4: Morphological alterations in the 24-hour nauplii population exposed to diazinon.

(A) asymmetric and widened appendages (arrows), (B) lack of hatching. Larvae are darker than controls (12.5X magnification) 
sensory function) and the third pair of appendages (mandibles with food capturing function) (Figure 6A).

-Persistent darker body color (Figure 6A).

-Deviation of the longitudinal body axis (Figures 6B).

\section{DISCUSSION}

There is no doubt that currently ecotoxicological bioassays have become an increasingly common research topic for scientists worldwide, mainly because of growing pollution of global environments, thus augmenting the number of toxicological studies and assays in this matter. Therefore, our group from the Laboratory of Reproduction Biology of the School of Medicine, University of Chile, proposed this study as a first step to determine and control polluted aquatic environments. Artemia salina was chosen as the testing organism, considering the feasibility of culturing large populations using laboratory methods, facility to manage, short term results given its short life cycle, its availability, low cost and the fact that it is found worldwide. The test substance, the organophosphorous pesticide diazinon, was chosen because of its massive and indiscriminate use, without proper legislation.

Among the methods developed to evaluate the potential effect of toxic substances are acute and chronic toxicity assays, in which the damaging effects of such substances are estimated through the response of the organisms exposed to a range of concentrations of the evaluated substance during brief periods of exposure (related to the length of the life cycle of the organism under study). Standardized toxicity assays allow for calibrating the toxicity of substances and the sensitivity of species to the substance or comparing the results to observations in the real environmental. They are repeatable, quick and easily interpreted. Moreover, mortality
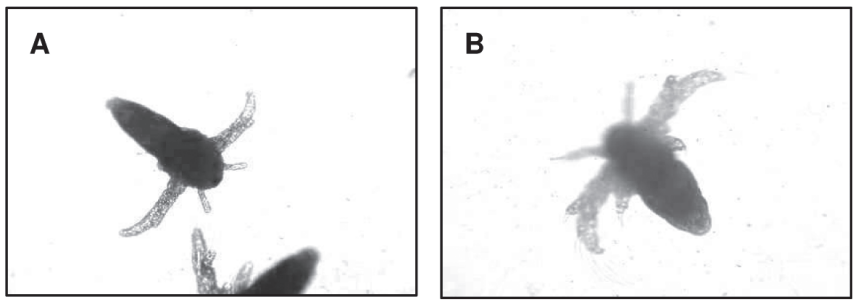

Figure 5: Morphological alterations in the 48-hour nauplii population exposed to diazinon.

(A) faulty development of the mandible (a) and lack of anal perforation (arrow) (9.4X magnification)
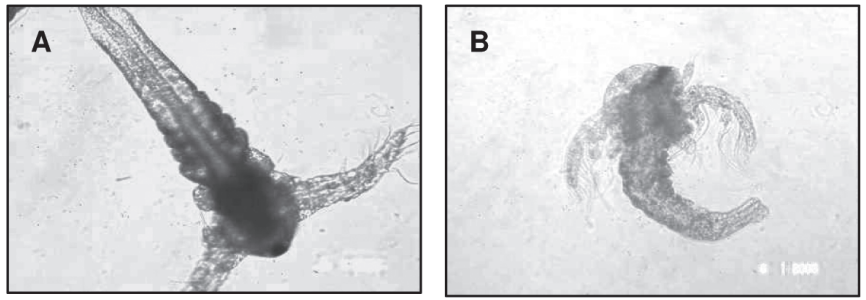

Figure 6: Morphological alterations in the 72-hour metanauplii population exposed to diazinon. (A) Agenesis of the first sensorial pair of appendages (a) and of the mandibles (b). (B) Deviation of the body axis. (7.5X magnification) is one of the most commonly used parameters in toxicity studies since, despite some limitations, it has demonstrated to be simple to interpret and easy to measure (Giesy \& Graney, 1989). According to our research, Artemia salina proves to be an excellent organism for studies, as reflected in scientific literature where it is a widely used species for toxicology tests, especially in studies for heavy metals as pollutants since the organism is highly sensitive to them. However, there were no registered studies for organophosphates; this is important considering the natural capacity of accumulation of these substances in Artemia sp. tissues, via direct contact or via direct ingestion by the digestive system and the secondary effects that might be observable in predators of Artemia salina in aquatic environments, taking into consideration that Artemia is part of the zooplankton and one of the first steps in aquatic trophic chains, as has been pointed out by Varó et al. (2003), which was the reason for electing an organophosphate as the toxicant for this study.

Therefore, since Artemia salina is a target organism for organophosphate pesticides (as an accumulator of toxicants), a high sensitivity against them is observed in comparison to the other organisms that belong to the aquatic fauna.

In conclusion, the microcrustacean Artemia salina is an easily managed organism. The culture of Artemia populations is easily obtained for acute and chronic toxicity bioassays. Artemia sp. is more sensitive to the exposure of the organophosphate diazinon in comparison to studies evaluating cadmium found in the literature. The observed effects -immobility of appendages/digestive system $\left(\mathrm{LD}_{50}\right)$ and morphological alterations in early development $\left(\mathrm{EC}_{50}\right)-$ in Artemia salina after 24 hours of exposure to diazinon is more representative than the effects of other exposure periods. There is a clear correlation between exposure time to diazinon and observed effects in the development of Artemia sp. larvae in terms of both of $\mathrm{LD}_{50}$ and $\mathrm{EC}_{50}$ (Fig. $2 \mathrm{c}$ $\mathrm{R}^{2}=0.92$ and Fig. $3 c \mathrm{R}^{2}=0.89$, respectively).

In summary, the microcrustacean Artemia salina proved to be an appropriate ecotoxicological bioindicator for aquatic environments polluted with organophosphate residues and is an important tool for future toxicology studies.

\section{REFERENCES}

BARNES J (1976) Toxic hazards to man. In: Metcalf, R, \& Mc Kelvey, J. The future for insecticides. Needs and prospects. New York USA pp: 145-150.

GIESY JP, GRANEY RL (1989) Recent developments in and intercomparasions of acute andchronic bioassays and bioindicators. Hydrobiologia 188(189): 21-60.

HEANO S, COREY G (1986) Plaguicidas organofosforados y carbámicos. Serie Vigilancia 2; OPS/OMS. Metepec, México. pp: 3-40.

HUBERT J (1980) Bioassays. Kendall/Hunt Publishing Company. Dubuque, Iowa. USA. pp: 65-97.

ORTEGA-CEREÑA J, ESPINOZA F, LÓPEZ L (1994) El control de los riesgos para la salud generados por los organofosforados en México. Retos ante el tratado de libre comercio. Salud Pública Mex. 36: 624632.

RODRÍGUEZ J, ESCLAPÉS M (1995) Protocolos estándares para bioensayos de toxicidad con 329 especies acuáticas. Versión 1.0. Gerencia General de Tecnología. Departamento de Ecología y Ambiente. INTEVEP. PDVSA. Venezuela. 109 pp.

SILVA G, CASALS P (2002) Bioensayo. Universidad de Concepción, 332 Facultad de Agronomía. htUtpR:/L/w:w w.multired.com/ciencia/ gosilagu/analisis\%20estadistico.htm

VARÓ I, AMAT F, NAVARRO J, BARREDA M, SERRANO R, 
HERNÁNDEZ F (2003) Exposure of Artemia sp (crustacea) cysts to the organophosphorous pesticide chlorpyfiros. Efficacy of the chorion as barrier. CICTA 2003. Porto-Portugal.

VARGAS A, BUSTOS-OBREGON E (2006) Bioensayo de toxicidad crónica utilizando poblaciones del Crustáceo Branquiópodo Artemia salina en distintas etapas del desarrollo temprano expuestas al Organofosforado diazinon. Revista Chilena de Educación Científica. 4: 20-32. 